\title{
SHEAR WAVE ANISOTROPY MEASUREMENTS ABOVE SMALL EARTHQUAKES IN TRICHONIS LAKE, GREECE
}

\section{Stavropoulou V. ${ }^{1}$, Giannopoulos D. ${ }^{1}$, Sokos E. ${ }^{1}$, Konstantinou K.I. ${ }^{2}$ and Tselentis G.-A.1,3}

${ }^{1}$ University of Patras, Department of Geology, Seismological Laboratory, 26504, Patras, Greece, basilikh18@gmail.com,dgiannopoulos@upatras.gr,esokos@upatras.gr,tselenti@upatras.gr

${ }^{2}$ Department of Earth Sciences, National Central University, Jhongli 320, Taiwan, kkonst@cc.ncu.edu.tw

${ }^{3}$ Institute of Geodynamics, National Observatory of Athens, Athens 11810, Greece, tselenti@noa.gr

\begin{abstract}
On April 2007, an earthquake swarm occurred in the vicinity of Trichonis Lake, western Greece. The seismic activity started on April 10 th 2007 after the occurrence of three moderate size earthquakes $M_{W}$ 5.0-5.2. We performed shear wave splitting measurements on seismic events recorded during the first week of the seismic activity by a portable network of 8 stations that was installed in the area by the University of Patras Seismological Laboratory. We were able to take measurements from 5 stations as the seismicity was concentrated mostly at the eastern part of the lake. Two splitting parameters were measured through the data processing, the time-delays between the fast and slow shear wave components and the polarization directions of the fast components. In general, the data analysis revealed the presence of shear wave anisotropy in the study area. The average value of normalized time-delays was calculated at $6.9 \pm 1.1 \mathrm{~ms} / \mathrm{km}$ while the fast polarization directions had an average of $130^{\circ} \pm 14^{\circ}$. The mean fast polarization directions were consistent with what is expected concerning the local stress field, as it was sub-parallel to the strike of the major faults at the eastern part of the lake and almost perpendicular to the direction of extension. Therefore, the findings can be interpreted by an anisotropic volume of stress-aligned micro-cracks within the upper crust according to the extensive dilatancy anisotropy model.
\end{abstract}

Keywords: shear wave splitting, seismic anisotropy, stress field, wave propagation.

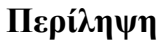

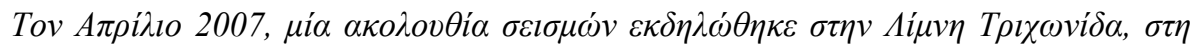

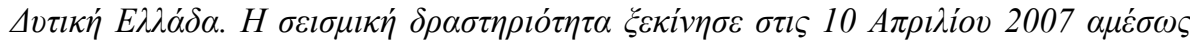

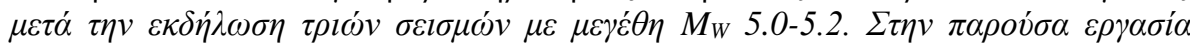

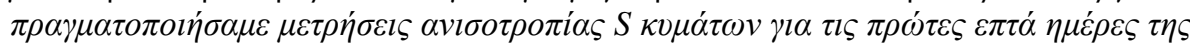

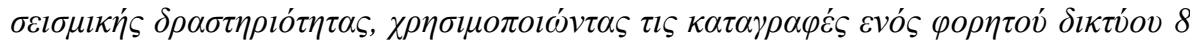

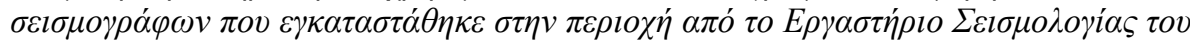

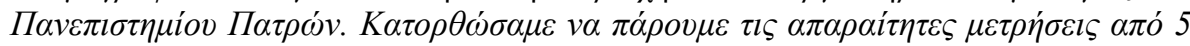

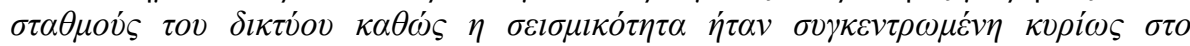

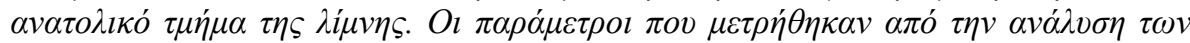

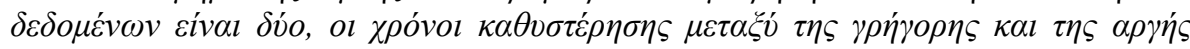




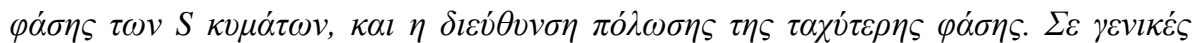

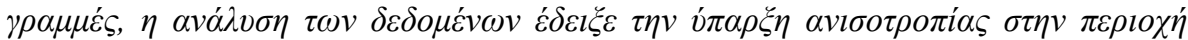

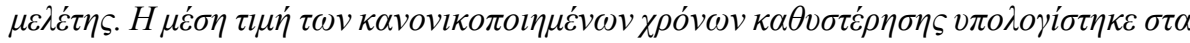

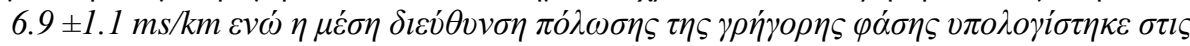

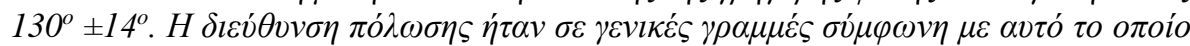

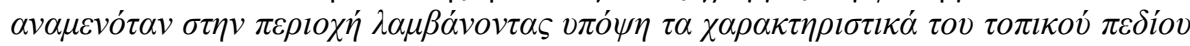

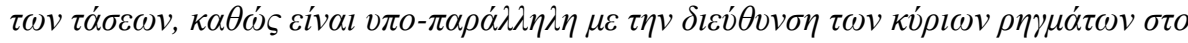

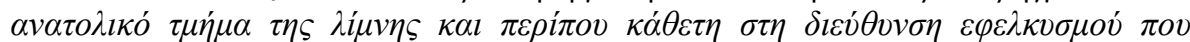

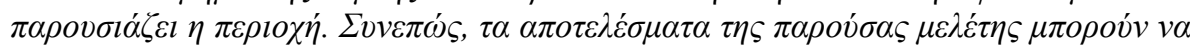

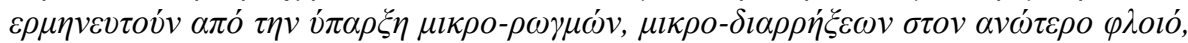

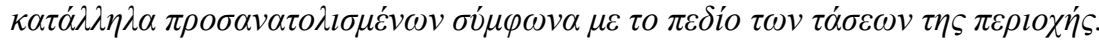

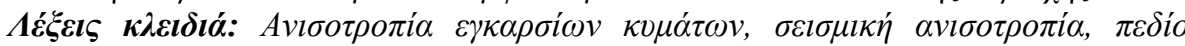
$\tau \alpha \dot{\sigma \varepsilon} \omega v, \delta l \alpha ́ \delta o \sigma \eta \kappa v \mu \alpha \dot{\tau} \omega v$.

\section{Introduction}

Shear wave splitting (SWS) is a phenomenon in which S waves are separated into two components with different polarization directions and propagation velocities. This occurs during $S$ wave propagation through an anisotropic medium (Crampin and Chastin, 2003; Crampin and Peacock, 2005). The two splitting parameters that can be measured through shear wave data processing are the polarization direction $\varphi$ of the fast component of the shear waves, and the time-delay $d t$ between the two components. Various models have been proposed to interpret the observed seismic anisotropy in the upper crust. The most widely accepted physical model, which is known as the extensive dilatancy anisotropy (EDA) model (Crampin, 1978, 1993, Crampin et al., 1984), explains the principal cause of the local SWS phenomenon as S wave propagation through stress-aligned, micro-cracks with orientations parallel/sub-parallel to the direction of the horizontal compression.

On April 2007, an earthquake sequence occurred at the eastern part of Trichonis Lake. The sequence initiated with small events on April $8^{\text {th }}$, 2007. Two days later three moderate size events $\mathrm{M}_{\mathrm{W}}$ 5.0-5.2 occurred within a time interval of 8 hours (April 10 th at 03:17, 07:15 and 10:41 GMT, hereafter called ' $\mathrm{T}_{1}$ ', ' $\mathrm{T}_{2}$ ' and ' $\mathrm{T}_{3}$ ', respectively), and then the seismic activity continued for about one month with smaller events. The major events and the spatiotemporal evolution of the 2007 earthquake swarm in Trichonis Lake was thoroughly studied by Kassaras et al. (2014), Sokos et al. (2010), Kiratzi et al. (2008) and Evangelidis et al. (2008). More specifically, according to Kiratzi et al. (2008), the earthquakes of the seismic swarm indicated a NNW-SSE strike of an activated structure, parallel to the eastern banks of Trichonis Lake, dipping to the NE and characterized by mainly normal faulting. The April 2007 earthquake swarm did not rupture the well documented E-W striking Trichonis normal fault that bounds the southern shore, but it was due to rupture of a NWSE normal fault that intersects at a $\sim 45^{\circ}$ angle to the Trichonis Fault (see Fig. 1). However, this observation is in contraction with the recent study of Kassaras et al. (2014), according to which, a sub-parallel structure situated approximately $3 \mathrm{~km} \mathrm{SW}$ of the aforementioned NW-SE normal fault, striking $\sim \mathrm{N} 310^{\circ}$ and dipping $\sim \mathrm{NE} 60^{\circ}$, with a length of $\sim 15 \mathrm{~km}$ and a width of $>10 \mathrm{~km}$, most probably hosted the three largest events of the April 2007 seismic swarm (see fig. 21 of Kassaras et al., 2014). Onshore, it has a dip-slip normal fault character becoming progressively left-lateral strike-slip and reverse/thrust toward the NNW, beneath the lake, according to the previous study. 


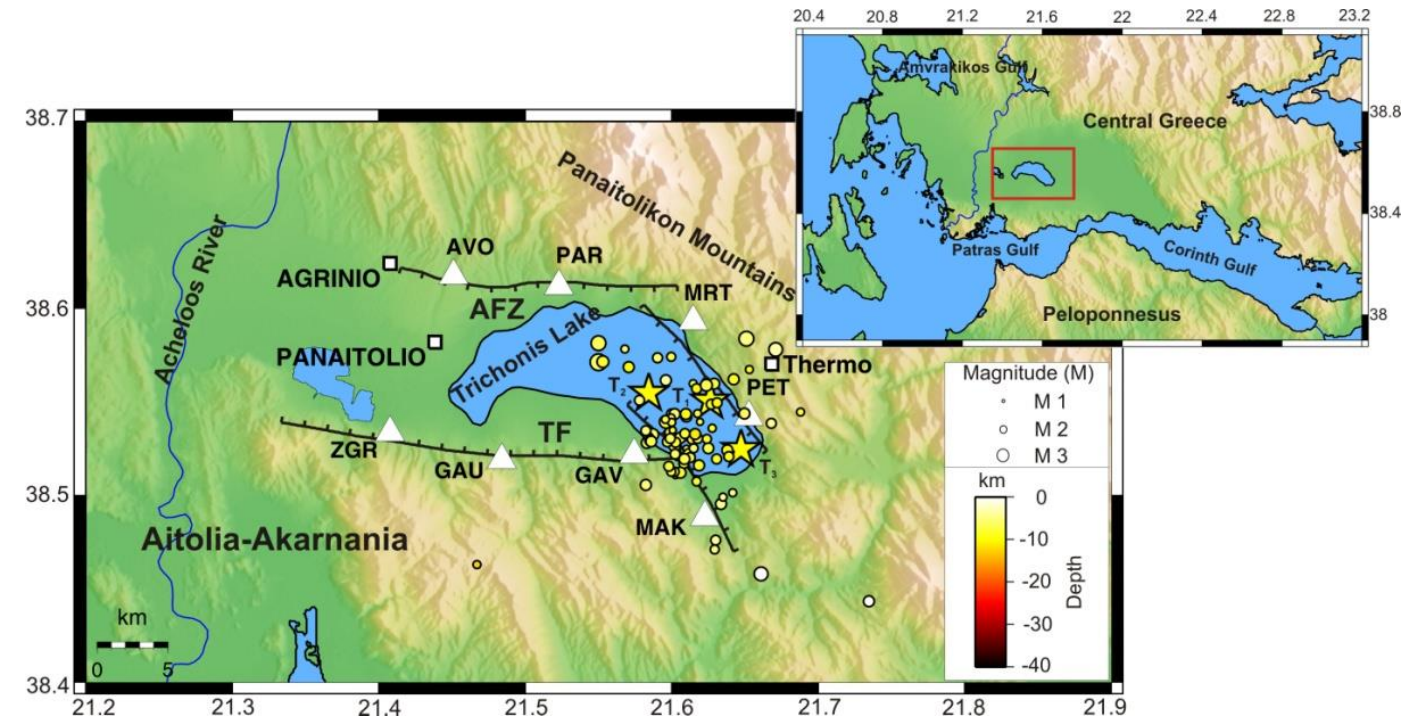

Figure 1 - Map of the study area in Trichonis Lake. Seismic stations used for the shear wave splitting measurements are shown as triangles. The seismic events (colored circles) from which the valid seismic results were obtained, the three major events $\left(T_{1}, T_{2}\right.$ and $T_{3}$ as stars) of the Trichonis earthquake sequence, major cities (squares) and major faults of Trichonis graben (Doutsos et al., 1987; Lekkas and Papanikolaou, 1997) are also shown. The depths of the events are color coded according to the color scale (bottom-right). The diameters of the circles are proportional to the magnitudes. AFZ: Agrinio Fault Zone; TF: Trichonis Fault.

In the present work, we first study the possible existence of shear wave anisotropy in the upper crust around the epicentral area of the 2007 Trichonis Lake earthquake swarm and then we interpret and discuss the measured parameters in relation with the local and the regional stress fields.

\section{Data and Methodology}

The University of Patras Seismological Laboratory (UPSL, http://seismo.geology.upatras.gr/) deployed a portable network of 8 stations in the study area (see Fig. 1) for twenty days (April $11^{\text {th }}$ 2007 - May $\left.1^{\text {st }} 2007\right)$ soon after the April $10^{\text {th }}$ three strongest events of the Trichonis earthquake swarm. Each station was equipped with three-component 4-Hz SIG borehole sensor, a 24-bit Earth Data recorder and a Global Positioning System (GPS) unit. The instruments have flat transfer function for velocity in the frequency range from $0.5 \mathrm{~Hz}$ to $50 \mathrm{~Hz}$. Recording was continuous with a sampling frequency of $100 \mathrm{sps}$.

For the purpose of this study, we used waveform data recorded during the first week of the seismic activity, from April $11^{\text {th }}$ to April $18^{\text {th }}$. The hypocentral locations were determined using the HYPOINVERSE software (Klein, 2002). The velocity model adopted was the one proposed by Rigo et al. (1996) for the neighbouring area of the western Gulf of Corinth and the magnitudes were computed using the coda duration method (Lee et al. 1972). The hypocentral location process resulted in a dataset of 77 earthquakes as the input of the splitting analysis, with focal depths ranging from $3 \mathrm{~km}$ to $11 \mathrm{~km}$ and magnitudes from 1.7 to 2.7 . The calculated mean location uncertainties were, $\mathrm{RMS}=0.13 \mathrm{~s}, \mathrm{ERZ}=0.95 \mathrm{~km}$ and $\mathrm{ERH}=0.67 \mathrm{~km}$.

The estimation of the splitting parameters was performed using a cross-correlation method (Ando et al., 1983). The seismograms were interpolated to 200 samples s $^{-1}$, integrated to displacement and then band-pass filtered between $1 \mathrm{~Hz}$ and $10 \mathrm{~Hz}$. The measurement window for each waveform was defined in the following way: the start of the window was fixed 0.05 s before the S-wave arrival while the endpoint was adjusted until the value of cross-correlation coefficient $\mathrm{C}$ between the fast 
and slow components was maximized. According to the cross-correlation method, both horizontal seismograms are rotated in the horizontal plane at $1^{\circ}$ increment of azimuth from $-90^{\circ}$ to $90^{\circ}$. Then, for each azimuth, the cross-correlation coefficient $\mathrm{C}$ is calculated between the two orthogonal seismograms, for a range of time-delays in a selected time window. When the absolute value of $\mathrm{C}$ reaches a maximum, the corresponding values of azimuth and time are chosen as the fast polarization direction and the time-delay between the separated shear waves, respectively. The measurement's uncertainty is estimated using a t-test at a $95 \%$ confidence level on the values of $\mathrm{C}$ as described by Kuo et al. (1994). We accept as valid the splitting measurements which conform to the following criteria: (a) the $\mathrm{C}$ value is larger than 0.80 , (b) the signal-to-noise ratio is larger than 2.5 , (c) the change of the measured $d t$ is less than $0.02 \mathrm{~s}$ when the window size is varied by $\pm 0.02 \mathrm{~s}$, and $(\mathrm{d})$ the change of the measured $\varphi$ is less than $10^{\circ}$ when the window size is varied by $\pm 0.02 \mathrm{~s}$. An example of a valid splitting measurement is shown in Fig. 2. The recordings, from which we calculated the splitting parameters, are derived from seismic events all located within the effective shear-wave window (Crampin and Gao, 2006) of every station (incidence angle $\leq 45^{\circ}$ ).

\section{GAV 2007416 19:42}
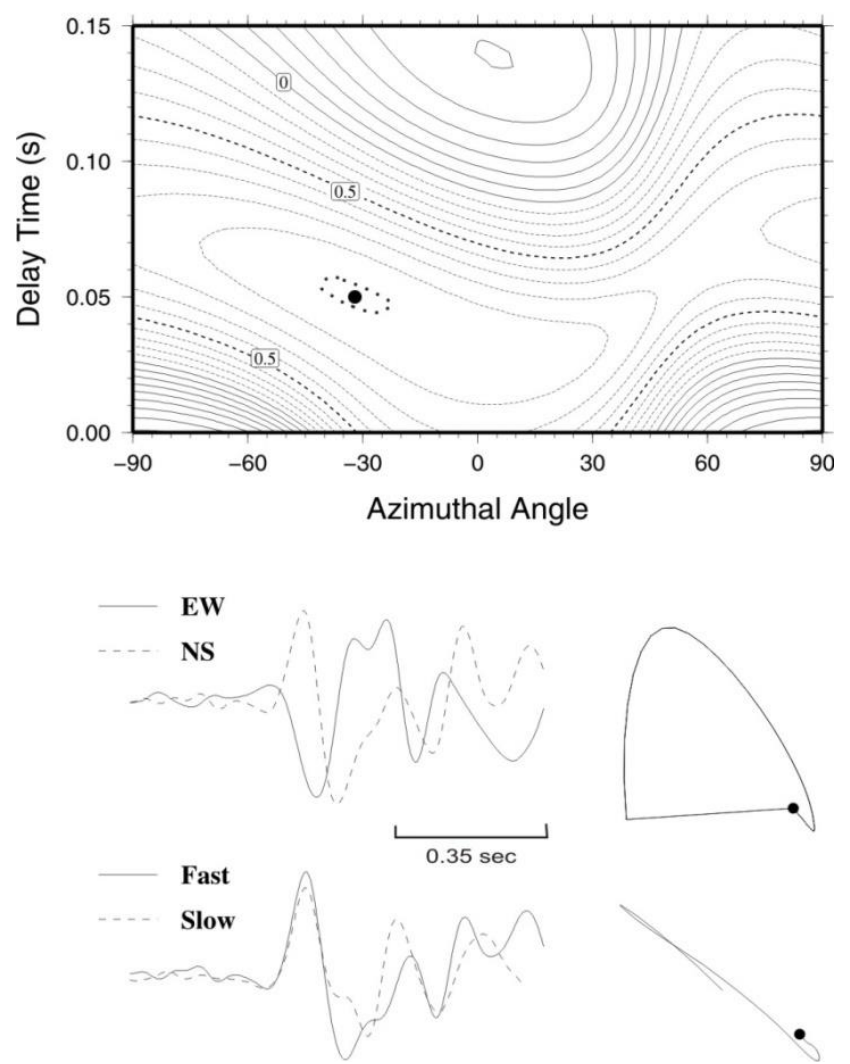

Figure 2 - An example of a valid splitting measurement of the shear waves recorded at the GAV station for an event that occurred in April 16, 2007. Upper panel: Contour diagram of the cross-correlation coefficient in the $(\varphi, d t)$ space. The preferred solution of $(\varphi, d t)$ corresponding to the maximum value (dot) is shown within the $95 \%$ confidence region (dotted line). Lower panel: Superposition of the horizontal components (upper traces), and the corrected fast and slow components (lower traces) once the splitting effects have been removed. Particle motions are shown to the right of each subpanel. 


\section{Results}

After the shear wave analysis we obtained 121 valid splitting measurements derived from 77 seismic events. Specifically, we obtained 46 valid measurements from GAV station, 16 from MAK, 25 from MRT, 31 from PET and only 3 measurements from PAR station. Zero measurements were obtained from stations GAU, ZGR and AVO as none of the analyzed seismic events was located within the effective shear wave window of these stations. Fig. 3 presents rose diagrams of the measured fast shear wave polarization directions. A first overview of the results using the complete data set shows the following: the time-delays, which were normalized according to the hypocentral distances, varied between $4.6 \pm 1.2 \mathrm{~ms} / \mathrm{km}$ at PET station, and $10.7 \pm 0.7 \mathrm{~ms} / \mathrm{km}$ at MRT station, with a mean value of $6.9 \pm 1.5 \mathrm{~ms} / \mathrm{km}$. The fast polarization directions varied between an average $\mathrm{E}-\mathrm{W}$ directions at PAR station and an average of a N-S direction at MRT station, exhibiting a mean of $130^{\circ} \pm 14^{\circ}$ (NW-SE). Table 1 gives a summary of the average values of the splitting parameters measured per seismic station.

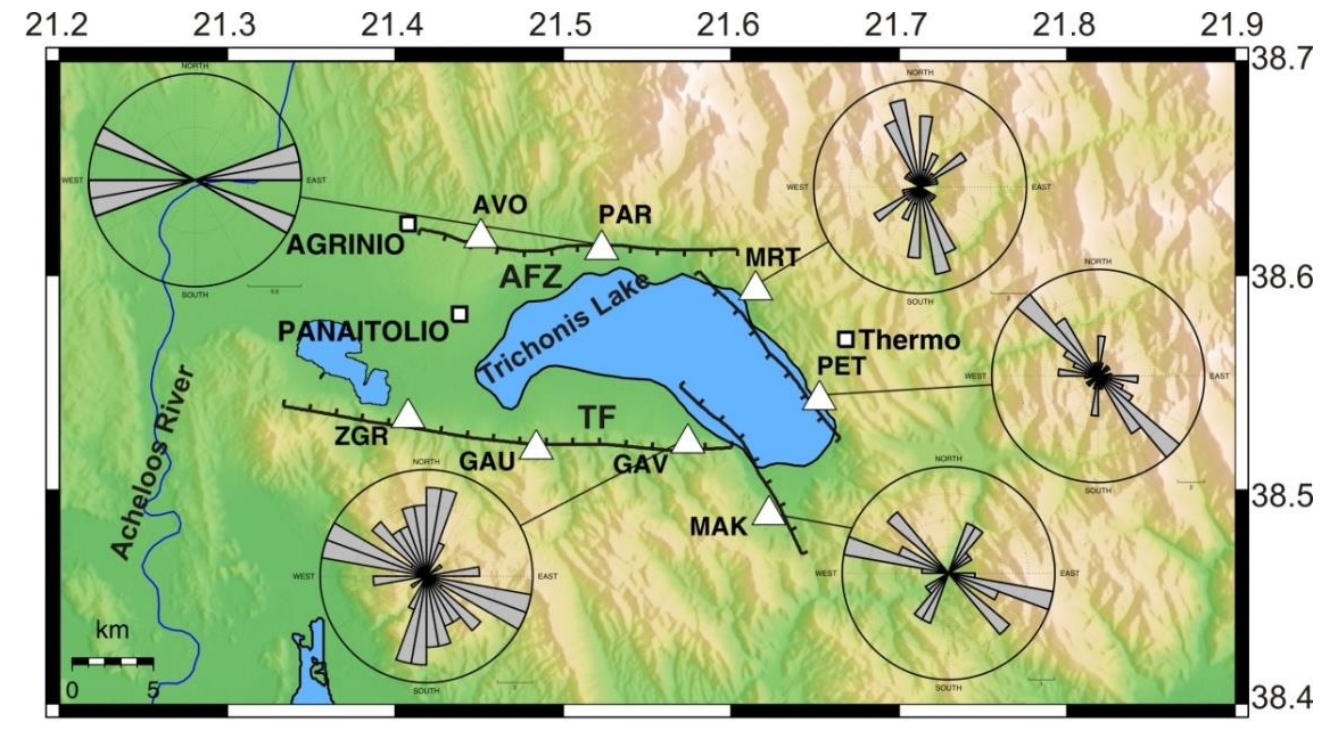

Figure 3 - Map of the study area showing rose diagrams of the measured fast shear wave polarization directions. Seismic stations, major cities and major fault traces are also presented as in Fig. 1.

Table 1 - Summary of the average values of the shear wave splitting parameters measured per seismic station.

\begin{tabular}{|l|c|c|c|c|}
\hline Station & Nobs & $\boldsymbol{\varphi}^{\mathbf{0}}$ & $\mathbf{d t}\left(\mathbf{m s ~ k m}^{-1}\right)$ & dt (ms) \\
\hline GAV & 46 & $149 \pm 11$ & $6.7 \pm 0.8$ & $57 \pm 11$ \\
\hline MAK & 16 & $104 \pm 17$ & $6.9 \pm 1.5$ & $57 \pm 15$ \\
\hline MRT & 25 & $177 \pm 15$ & $10.7 \pm 0.7$ & $106 \pm 8$ \\
\hline PAR & 3 & $91 \pm 8$ & $5.3 \pm 1.3$ & $43 \pm 10$ \\
\hline PET & 31 & $134 \pm 18$ & $4.6 \pm 1.2$ & $42 \pm 10$ \\
\hline
\end{tabular}

Note: Nobs denote the number of observations per station, $\phi$ is the mean of the fast polarization directions based on directional statistics, $d t\left(\mathrm{~ms} \mathrm{~km}^{-1}\right)$ is the average time delays normalized according to the hypocentral distance and $d t(\mathrm{~ms})$ is the average absolute time delays. 


\section{Interpretation and Discussion}

The active graben (Doutsos et al., 1987) in the broader area of Trichonis Lake is considered as one of the key areas for the study of the regional seismotectonic processes of western Greece, as it lies between other active structures, e.g. the Corinth, Patras and Amvrakikos gulfs, in an almost parallel direction to them. Various multidisciplinary observations around Trichonis Lake, indicate an approximately on-going N-S direction of extension in the area (see Introduction section).

The majority of the epicenters of the 2007 swarm were concentrated mostly within the eastern part of the lake, which is bounded by two NNW-ESE trending normal faults (Kiratzi et al., 2008) (see Fig. 4). According to Kiratzi et al. (2008) the focal mechanisms of the 2007 swarm indicate mostly normal faulting along NNW-SSE trending planes. The parameters of the resulting average mechanism for all the 2007 events as well as of the three major events are presented in Table 2 .

Table 2 - Parameters of the resulting average mechanism for all the events of the April 2007 seismic swarm in Trichonis Lake, as well as for the three major seismic events.

\begin{tabular}{|l|c|c|c|c|c|c|c|c|c|c|}
\hline & \multicolumn{3}{|c|}{ Nodal plane 1 } & \multicolumn{3}{c|}{ Nodal plane 2 } & \multicolumn{2}{c|}{ P axis } & \multicolumn{2}{c|}{ T axis } \\
\cline { 2 - 12 } & Strike $^{\circ}$ & Dip $^{\circ}$ & Rake $^{\circ}$ & Strike $^{\circ}$ & Dip $^{\circ}$ & Rake $^{\circ}$ & $\mathrm{az}^{\circ}$ & $\mathrm{pl}^{\circ}$ & $\mathrm{az}^{\circ}$ & $\mathrm{pl}^{\circ}$ \\
\hline $\begin{array}{l}\text { Swarm } \\
\text { average }\end{array}$ & 325 & 52 & -58 & 99 & 48 & -124 & 298 & 65 & 33 & 2 \\
\hline $\mathrm{T}_{1}$ & 325 & 59 & -72 & 113 & 35 & -117 & 274 & 70 & 42 & 12 \\
\hline $\mathrm{T}_{2}$ & 317 & 60 & -67 & 97 & 37 & -124 & 271 & 67 & 31 & 12 \\
\hline $\mathrm{T}_{3}$ & 325 & 64 & -65 & 98 & 35 & -131 & 275 & 62 & 37 & 16 \\
\hline
\end{tabular}

Note: Parameters as presented in Kiratzi et al. (2008). az and pl denote the azimuths and plunges of $\mathrm{P}$ - and $\mathrm{T}$-axis, respectively. $\mathrm{T}_{1}, \mathrm{~T}_{2}$ and $\mathrm{T}_{3}$ denote the three largest events of the seismic swarm that occurred on April 10 ${ }^{\text {th }}$ at 03:17, 07:15 and 10:41 GMT, respectively.

The resulting average source parameters of the 2007 events, as well as the source parameters of the three strongest events of the swarm, indicated an approximately NE-SW extension which is almost perpendicular to the observed $\mathrm{NW}$-SE $\left(130^{\circ} \pm 14^{\circ}\right)$ fast polarization directions determined in this study (see Fig. 4). We suggest that the observed $\sim$ NW-SE fast shear wave polarization direction is caused by stress-aligned micro-cracks, oriented parallel or sub-parallel to the trend of faulting at the eastern part of the lake and perpendicular to the direction of the extension. The observed direction of $\varphi$ seems to be in a good agreement with the presence of a secondary local NE-SW extension at the eastern part of the lake, within the prevailing N-S regional extension.

As it was mentioned before, according to Kiratzi et al. (2008), the April 2007 earthquake swarm did not rupture the well documented E-W striking Trichonis normal fault (TF) that bounds the southern shore, but it is due to rupture of a NW-SE normal fault that strikes at a $\sim 45^{\circ}$ angle to the Trichonis Fault. The fast polarization directions that were measured at GAV station are characterized by two main trends, one with a $\sim$ NNW-SSE direction and a second one with a $\sim$ WNW-ESE direction (see Fig. 3). The observed fast polarization directions at GAV station seem to be affected by the presence of the aforementioned two structures, as the station is located above their junction. In this case, $\varphi$ is possibly reflecting the orientation of two main groups of micro-cracks, with orientations parallel to the trend of the two faults. 


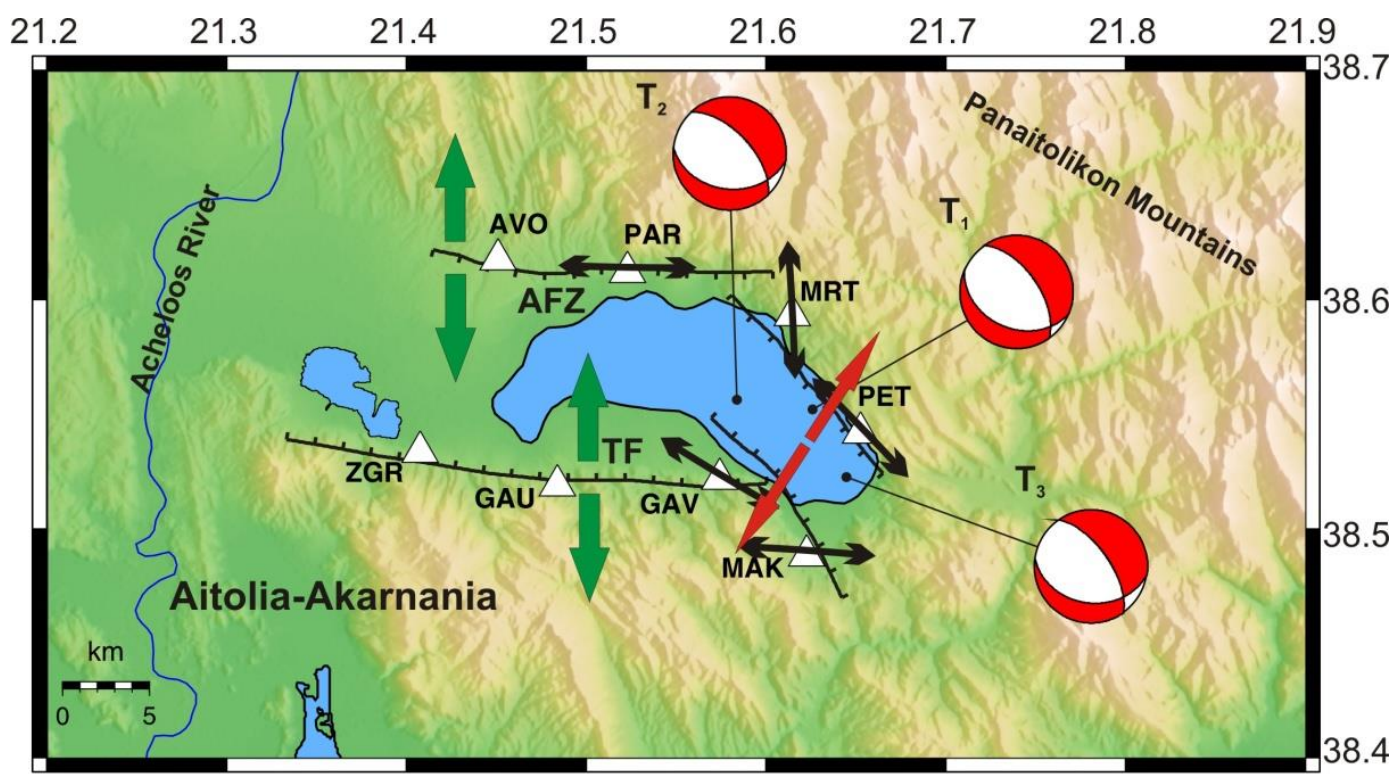

Figure 4 - Map of the study area presenting the mean values of the fast polarization directions that were measured at each station (black arrows). The direction of regional extension (green arrows) is after Bernard et al. (2006). The beachballs refer to the focal mechanisms for the three strongest events $\left(T_{1}, T_{2}\right.$ and $\left.T_{3}\right)$ of April $10^{\text {th }}$ 2007, with $M w$ 5.0-5.2, as determined by Kiratzi et al. (2008). The red arrows represent the orientation of the T-axis $\left(\right.$ azimuth $=3^{\circ}$ ) of the resulting average mechanism for all the 2007 events, as determined by the previous study also. Seismic stations, major cities and major fault traces are also presented as in Fig. 1.

Fast polarization directions measured at different stations show in some cases an up to $90^{\circ}$-flip fro $\mathrm{m}$ the observed NW-SE $\left(130^{\circ} \pm 14^{\circ}\right)$ mean direction (see Fig. 3). Such cases of up to $90^{\circ}$-flip above small earthquakes in the vicinity of seismogenic faults has been reported in several studies (e.g. Crampin et al., 2002) that have indicated a key role for over-pressured fluids in the splitting parameters. The presence of over-pressured fluids in the epicentral area of the 2007 seismic swarm and the possible involvement of fluids circulation in depth was suggested by Kassaras et al. (2014) as an additional possible scenario for the observed strong stress heterogeneity of the study area. We suggest that the cause of the observed deviations between the fast polarization directions was a possible migration of fluids through the fractured damage zone which possibly allowed local rotations of the principal stress axis. This suggestion could also explain to some extent, the differences between the average normalized time-delay values per station (see Table 1). These differences were likely to reflect different saturation levels of the stress-aligned micro-crack systems.

It is noteworthy to mention the mean fast polarization direction that was measured at PAR station, despite the fact that we were able to take only 3 valid measurements at this station. PAR station is located at the north shore of the lake, northwest from the area of the studied seismicity and the epicenters of the three strongest events. Fast polarization directions show a mean value of $91^{\circ} \pm 8^{\circ}$ parallel to the strike of the Agrinio Fault Zone. The $\varphi$ measured at PAR station is in agreement with the regional stress field, being perpendicular to the direction of the extension of the broader area. The observed fast polarization directions at this station were not affected by the presence of the secondary local stress field at the eastern part of the lake. 


\section{Conclusions}

The results presented in this study can be summarized as follows:

(i) the data analysis revealed the existence of an anisotropic upper crust at the eastern part of Trichonis Lake, as shear wave splitting processes were observed in all stations at which a valid splitting measurement was feasible.

(ii) fast polarization directions presented a general NW-SE orientation $\left(130^{\circ} \pm 14^{\circ}\right)$, which is in agreement with the presence of a local extensional stress field at the eastern part of Trichonis Lake.

(iii) shear wave splitting at the study area was most probably caused by stress aligned fluid-filled micro-cracks and micro-fractures that were oriented parallel or sub-parallel to the trend of faulting.

(iv) the results of this work confirm in some extent the NW-SE trend of the activated fault zone at the eastern part of the lake according to previous studies.

\section{Acknowledgments}

The figures were created using the Generic Mapping Tool software (Wessel and Smith 1998) (http://www.soset.hawaii.edu/gmt/). Data analysis performed using the Seismic Analysis Code software that was developed at Lawrence Livermore National Laboratory, CA, USA.

\section{References}

Bernard, P.H., Lyon-Caen, P., Briole, A., Deschamps, F., Boudin, K., Makropoulos, P., Papadimitriou, F., Lemeille, G., Patau, H., Billiris, D., Paradissis, K., Papazissi, H., Castarède, O., Charade, A., Nercessian, A., Avallone, F., Pacchiani, J., Zahradnik, S. and Sacks Linde, A., 2006. Seismicity, deformation and seismic hazard in thewestern rift of Corinth: new insights from the Corinth Rift Laboratory (CRL), Tectonophysics, 426, 7-30.

Crampin, S. and Chastin, S., 2003. A review of shear wave splitting in the crack-critical crust, Geophys. J. Int., 155, 221-240.

Crampin, S. and Peacock, S., 2005. A review of shear-wave splitting in the compliant crack-critical anisotropic Earth Wave Motion, 41, 59-77.

Crampin, S., 1978. Seismic wave propagation through a cracked solid: polarization as a possible dilatancy diagnostic, Geophys. J. R. Astron. Soc., 53, 467-496.

Crampin, S., 1993. Arguments for EDA, Can. J. Exp. Geophys., 29, 3-17.

Crampin, S., Evans, J.R. and Atkinson, B.K., 1984. Earthquake prediction: a new physical basis, Geophys. J. R. Astron. Soc., 76, 147-156.

Crampin, S. and Gao, Y., 2006. A review of techniques for measuring shear-wave splitting above small earthquakes, Phys. Earth. Planet. Inter., 159, 1-14.

Crampin, S., Volti, T., Chastin, S., Gudmundsson, A. and Stefánsson, R., 2002. Indication of high pore-fluid pressures in a seismically-active fault zone, Geophys. J. Int., 151, F1-F5.

Doutsos, T., Kontopoulos, N. and Frydas, D., 1987. Neotectonic evolution of northwestern continental Greece, Geol. Rundsch, 76, 433-450.

Doutsos, T., Piper, G., Boronkay, K. and Koukouvelas, I., 1993. Kinematics of the Central Hellenides, Tectonics, 12, 936-953.

Evangelidis, C.P., Konstantinou, K.I., Melis, N.S., Charalambakis, M. and Stavrakakis, G.N., 2008. Waveform relocation and focal mechanism analysis of an earthquake swarm in Trichonis Lake, Western Greece, Bull. Seismol. Soc. Am., 98(2), 804-811.

Kassaras, I., Kapetanidis, V., Karakonstantis, A., Kaviris, G., Papadimitriou, P., Voulgaris, N., Makropoulos, K., Popandopoulos, G. and Moshou, A., 2014. The April-June 2007 Trichonis 
Lake earthquake swarm (W. Greece): New implications toward the causative fault zone, $J$. Geodyn., 73, 60-80.

Kiratzi, A., Sokos, E., Ganas, A., Tselentis, A., Benetatos, C., Roumelioti, Z., Serpetsidaki, A., Andriopoulos, G., Galanis, O. and Petrou, P., 2008. The April 2007 earthquake swarm near Lake Trichonis and implications for active tectonics in western Greece, Tectonophysics, 452, 51-65.

Klein, F.W., 2002. User's guide to HYPOINVERSE-2000, a FORTRAN program to solve earthquake locations and magnitudes, U.S. Geological Open File Report 02-606, Version 1.0.

Kuo, B.Y., Chen, C.C. and Shin, T.C., 1994. Split S waveforms observed in northern Taiwan: implications for crustal anisotropy, Geophys. Res. Lett., 21, 1491-1494.

Lee, W.H.K., Bennett, R.E. and Meagher, K.L., 1972. A method of estimating magnitude of local earthquakes from signal duration, Open File Report, U. S. Geological Survey, 28 pp.

Lekkas, E. and Papanikolaou, D., 1997. Neotectonic Map of Greece, Aitolia-Akarnania sheet (scale 1:100.000), Applied Scientific Program, University of Athens, Dept of Dynamic, Tectonic and Applied Geology, Technical report, 148 pp.

Rigo, A., Lyon-Caen, H., Armijo, R., Deschamps, A., Hatzfeld, D., Makropoulos, K., Papadimitriou, P. and Kassaras, I., 1996. A microseismicity study in the western part of the Gulf of Corinth (Greece): implications for large-scale normal faulting mechanisms, Geophys. J. Int., 126, 663-688.

Sokos, E., Pikoulis, V.E., Psarakis, E.Z. and Lois, A., 2010. The April 2007 swarm in Trichonis Lake using data from a microseismic network, Proceedings of the $12^{\text {th }}$ International Congress, Bulletin of the Geological Society of Greece, Patras, May, 2010, XLIII/4, 21832192.

Wessel, P. and Smith, W.H.F., 1998. New improved version of the Generic Mapping Tools Released, EOS, Trans. Am. Geophys. Un., 79, 529. 